\title{
Universalização do princípio da simetria? Debates em torno da democratização epistêmica e da emergência de uma "era da pós- verdade"
}

\author{
Carolina Faraoni Bertanha' \\ Recebido em março de 2020 \\ Aceito em junho de 2020
}

\begin{abstract}
RESUMO
O objetivo deste artigo é examinar os debates recentes na área dos Science and Technology Studies acerca da emergência de uma era da pós-verdade e as potenciais responsabilidades do campo na influência que emoções e crenças pessoais têm na formação da opinião pública, em detrimento de fatos ditos objetivos. Trata-se de um exercício ensaístico, em que focamos na relação entre essa suposta era da pós-verdade e um princípio basilar para a área: o princípio da simetria, que prevê o tratamento equivalente de crenças verdadeiras ou falsas por parte do sociólogo interessado na análise do conhecimento científico. Procuramos, assim, refletir sobre a temática da democratização epistêmica, discutindo sua possível ligação com a emergência de uma era da pós-verdade.
\end{abstract}

Palavras-chave: Pós-verdade; Princípio da Simetria; Science and Technology Studies; Democratização Epistêmica.

\section{Universalization of the symmetry principle? Debates around epistemic democratization and the emergence of a "post-truth era"}

\begin{abstract}
This paper aims to examine the recent debates in the field of Science and Technology Studies about the emergence of a post-truth era and the potential responsibilities of the field in influencing personal emotions and beliefs in the formation of public opinion, to the detriment of so-called objective facts. It's an essay that focuses on the relationship between this supposed post-truth era and a basic principle for this particular field: the principle of symmetry, which predicts an equivalent treatment to true or false beliefs by the sociologist interested in the analysis of scientific knowledge. Thus, we seek to reflect on the theme of epistemic democratization, discussing its possible link with the emergence of a post-truth era.
\end{abstract}

Keywords: Post-truth; Symmetry Principle; Science and Technology Studies; Epistemic Democratization.

\footnotetext{
${ }^{1}$ Doutoranda do Programa de Pós-Graduação em Sociologia da Universidade de Brasília, Brasília, Brasil. É membro do grupo de pesquisa Ciências, Tecnologias e Públicos (http://dgp.cnpq.br/dgp/espelhogrupo/1937994639028677) e bolsista do Conselho Nacional de Desenvolvimento Científico e Tecnológico (CNPq). Contato: carolfbertanha@gmail.com.
} 


\section{Introdução}

A área interdisciplinar que se convencionou chamar de Science and Technology Studies (STS), cujo foco central está na análise voltada às influências do contexto social e na relativa determinação do conteúdo do conhecimento científico, esteve envolvida em discussões e dissensos desde seus trabalhos fundantes (PREMEBIDA et al, 2011). Em retrospecto, é notável o dessabor que a pioneira proposta do Programa Forte da sociologia do conhecimento elaborada por David Bloor e colaboradores, cuja preocupação central era "trazer a ciência para o âmbito do escrutínio cabalmente sociológico" por meio do tratamento simétrico das crenças verdadeiras e falsas, ao científico e ao social (BLOOR, 2009, p.16), causou a Thomas Kuhn. O autor da basilar obra As estruturas das revoluções científicas, reconhecida fonte inspiradora, comentou, posteriormente, que "não se falará de nada que mereça ser chamado de ciência caso se exclua o papel da natureza" (KUHN, 2003, p.380), procurando desvencilhar-se das acusações de relativismo remetidas a ele e à sua obra.

Por sua vez, a subsequente generalização do princípio da simetria do Programa Forte proposta por Bruno Latour e Steve Woolgar (1997), Bruno Latour (2004; 2011; 2012), Michel Callon (1984), John Law (1992; 2004), entre outros, colocou em pauta a necessidade de estender a equivalência e a simetria analítica também entre humanos e não humanos nos processos sociotécnicos (PREMEBIDA et al, 2011). Esse movimento angariou novas e intensas disputas no campo, gerando manifestos autodenominados anti-latourianos (BLOOR, 1999) e respostas igualmente ácidas aos "ataques sistemáticos" à dita generalização "obscura e mal interpretada" do princípio da simetria por parte de Latour (1999) e seus companheiros franceses. Este, ainda, foi um dos protagonistas do debate epistemológico que marcou a "guerra das ciências" nos anos de 1990, acusado de propagar, junto a outros filósofos e sociólogos, "uma coleção de abusos extremos", ou "imposturas intelectuais" em relação à prática científica e ao conceito de verdade (SOKAL; BRICMONT, 2001).

Dessa forma, acusações recorrentes de anticientificismo, pós-modernismo, antirracionalismo e, principalmente, relativismo epistêmico pairaram constantemente 
no céu dos Science Studies, grande parte derivada de questões epistemológicas, ontológicas e metodológicas relacionadas ao princípio da simetria (MATTEDI, 2004). O final da década de 2010 não eximiu os STS de novas disputas, polêmicas, réplicas e tréplicas. Um recente embate tomou forma nas páginas de dois dos principais periódicos da área, o Social Studies of Science e o Engaging Science, Technology, and Society, mas não exclusivo a eles. Diversos pesquisadores influentes na área se posicionaram em editoriais, artigos, respostas e postagens, como Sismondo (2017a, 2017b), Collins et al (2017), Lynch (2017), Jasanoff e Simmet (2017), entre outros, inflamados por polêmicas asserções levantadas pelo filósofo Steve Fuller (2016a; 2016b; 2018), relacionadas à generalização do princípio da simetria e à potencial responsabilidade do campo na emergência de uma suposta "era da pós-verdade”. Steve Fuller (2018, p.58) afirma explicitamente que "a pós-verdade é a filha que os STS têm sempre tentado deserdar", propondo ainda que "nós, [pesquisadores de STS], devemos finalmente abraçar nossa responsabilidade pelo mundo da pós-verdade”2. O autor argumenta que esse mundo pós-factual é o resultado inevitável de um processo de “democratização epistêmica”, promovido, segundo o mesmo, pela "universalização da simetria” proposta por Bruno Latour, que por sua vez não teria previsto que "qualquer pessoa poderia aplicar esse princípio por si mesmo, e não apenas aqueles interessados em estudar a tecnociência” (FULLER, 2016b, p.03). Fuller utiliza-se, para tanto, da definição do dicionário Oxford, que declarou "pós-verdade" a palavra do ano de 2016, dedicando-a à eleição de Donald Trump para a presidência dos Estados Unidos e ao referendo britânico de saída da União Europeia, o Brexit. O importante dicionário define a palavra como um adjetivo que "relaciona-se com ou denota circunstâncias em que fatos objetivos são menos influentes em moldar a opinião pública do que apelos à emoção e às crenças pessoais" (POSTTRUTH, 2016, s/p).

Como apontamos, as incisivas proposições de Fuller não passaram batido nos STS a partir, principalmente, do ano de 2017. Apesar das diferentes agendas de pesquisa e filiações a que os autores citados acima se remetem, além, claro, de seus posicionamentos em relação à responsabilidade ou não da área, um exame preliminar

\footnotetext{
${ }^{2}$ Esta e todas as demais traduções de citações para o português foram feitas de forma livre pela autora.
} 
da discussão suscita um conjunto de questões compartilhadas: a que se remete Steve Fuller ao falar em uma era da pós-verdade? Qual a relação que pode ser feita com o princípio da simetria, seja em sua conceptualização no Programa Forte, seja na generalização promovida pela Teoria Ator-Rede (TAR), com a ideia de uma democratização epistêmica? E, ainda mais importante, o que os STS teriam a ver com a emergência, formação e circulação de pós-verdades? A crítica de Fuller indicaria que o perigo cresceu no nosso quintal?

Tendo em vista essas questões e o recente embate em questão, o objetivo deste ensaio é mapear e examinar as discussões atuais no campo em torno da emergência de uma "era da pós-verdade" e sua relação com os STS, apontando para as críticas mobilizadas por alguns expoentes da área. Para tanto, primeiramente analisamos a noção de pós-verdade. Em seguida damos atenção ao desenvolvimento do princípio da simetria pelo Programa Forte, sua generalização ambicionada por autores filiados à TAR e movimentos posteriores3, e a universalização do princípio proposto por Fuller. Seguindo os argumentos deste autor, focamos no papel que a dessacralização do conhecimento científico enquanto fonte epistêmica confiável de informação promovida pelo Programa Forte e outras correntes ligadas aos STS, assumem em direção à uma dita democratização epistêmica ${ }^{4}$. Neste ponto, tecemos críticas à sua interpretação da relação entre o princípio da simetria e a democratização epistêmica, apontando que se trata de uma análise assimétrica que desconsidera as dificuldades que os públicos nãoexperts enfrentam quando da tentativa de participação em espaços de tomada de decisão (LYNCH, 2017; SISMONDO, 2017a; 2017b).

\footnotetext{
3 Atualmente fala-se em um movimento "pós-TAR". Para mais considerações, ver Law e Hassard (1999), Law (2004) e Mol (2002).

${ }^{4}$ É importante salientar que a Sociologia do Conhecimento Científico proposta pelo Programa Forte, entre outras correntes ligadas aos STS, não foram as únicas a tratarem do estatuto epistêmico do conhecimento, da verdade e dos fatos científicos ao longo do século XX. Entretanto, no que diz respeito à Sociologia do Conhecimento, à Sociologia da Ciência, e aos STS em particular, o Programa Forte foi um ponto de ruptura decisiva em relação à forma como os estudos sociológicos abarcavam a ciência anteriormente, especialmente inspirados por Robert Merton em sua análise dos aspectos institucionais das comunidades científicas. Como aponta Duarte (2015), o Programa Forte rompeu tanto com a tradição mertoniana quanto durkheimiana, apesar de influenciado por este último, exatamente por propor explicar por meio de fatores de ordem sociológica a própria natureza e o conteúdo do conhecimento científico. Assim, "a grande ruptura em jogo consistiu no abandono da ideia de que a ciência possuiria uma racionalidade de cunho extra-social que definiria a sua natureza e justificaria a verdade - ou, ao menos, a possibilidade de progresso rumo à verdade - de seus enunciados" (DUARTE, 2015, p.74).
} 
Por fim, discutimos a relação de coprodução entre democracia e pós-verdade, buscando argumentar que não há uma ligação causal observável historicamente entre uma democratização epistêmica e uma nova era em que as bases factuais são ignoradas a favor das volições políticas de um grupo ou outro (JASANOFF; SIMMET, 2017).

\section{O que é, afinal, a pós-verdade?}

A palavra pós-verdade pode assumir diversas acepções, ligadas ou não à ascensão de governantes promovedores de fatos alternativos, como Trump e o próprio presidente do Brasil, Jair Bolsonaro, de grupos de direita interessados na "manutenção da família tradicional" ou de escândalos envolvendo a manipulação de eleitores em redes sociais. Sismondo (2017b, p.588) comenta que há seis temas prevalecentes na ideia de pós-verdade e na emergência de uma era marcada por esse sentido: 1) A definição glosada pelo dicionário Oxford, que salienta que as emoções têm importado mais no julgamento do que é verdade, seja na política ou na cultura pública, do que as bases factuais nas quais ela se assenta; 2) Opiniões, especialmente se elas vão de encontro ao que as pessoas já querem acreditar, têm importado mais do que os fatos; 3) Figuras públicas podem fazer afirmações desconectadas dos fatos, sem temer consequências; 4) Aceitação da desonestidade como parte da vida política; 5) A perda de confiança na mídia tradicional, levando à proliferação de notícias falsas e à promoção de investigações desvinculadas dos sistemas tradicionais de construção de conhecimento, seja científico ou não; 6) E, por fim, a perda de respeito ou de confiança na expertise científica.

Assim, apesar do uso da palavra remontar ao início dos anos de 1990, a recente ressurreição do termo associa-se a acusações de mentiras recorrentes e falsas premissas políticas, tendo se tornado uma queixa constante sobre a "difundida, flagrante, sem remorso e frequentemente bem-sucedida da enganação promovida por agentes poderosos" (LYNCH, 2017, p.594). Os seis temas elencados por Sismondo e a definição exibida acima possuem similitudes. Entretanto, como bem observa o próprio Sismondo (2017b), qual seria a ligação entre essas definições, e as reflexões, pesquisas e questões teóricas e metodológicas arroladas pelos STS? No que concerne à controversa sugestão 
trazida por Steve Fuller, a resposta encontra ressonância no sexto tema elencado por Sismondo, a perda de respeito ou de confiança na expertise científica.

Para Fuller (2016a), a ligação entre a ideia de pós-verdade e o campo científico em questão encontra sua origem ainda no influente pensamento de Thomas Kuhn, em sua visão, um "relato pós-verdadeiro da ciência". Seria pós-verdadeiro pois, segundo a interpretação deveras radical dos postulados de Kuhn quanto às revoluções científicas, a verdade

[...] não é mais o árbitro do poder legítimo, mas sim a máscara de legitimidade usada por todos em busca do poder. A verdade é apenas mais um - talvez o mais importante - recurso em um jogo de poder sem fim. Nesse sentido, a ciência difere da política apenas em que as máscaras de seus jogadores raramente caem (FULLER, 2016a, s/p).

Ao postular que a verdade é apenas um recurso em um jogo de poder, aproximando-se da política e distanciando-se da objetividade dos fatos, marca da prática científica moderna, Fuller (2016a) implicitamente nega qualquer distinção entre o conhecimento científico e o não científico, característica compartilhada entre os trabalhos desenvolvidos em STS, no geral. Seu posicionamento, entretanto, é crítico: ao equivaler ciência e política, afirma posteriormente que os STS têm o crédito de ter tornado essa equivalência uma rotina em sua prática de pesquisa, ao mesmo tempo em que proporcionou ao público em geral quatro tropos comuns à pós-verdade: 5

1. Ciência é o que resulta uma vez que um artigo científico é publicado, não o que possibilitou a publicação do artigo, já que a condução de fato da pesquisa está sempre aberta a múltiplas e opostas interpretações; 2. O que passa pela "verdade" na ciência é uma contingência institucionalizada, a qual uma vez que se os cientistas estejam fazendo seu trabalho, será eventualmente derrubada e substituída, até porque essa pode ser a única maneira de avançar em seus campos. 3. O consenso não é um estado natural na ciência, mas um que requer fabricação e manutenção, trabalho que é facilmente subestimado porque a maioria deste trabalho ocorre fora do palco no processo de revisão por pares. 4. As principais categorias normativas da ciência, como 'competência' e 'expertise', são como as datas móveis do calendário de festas cristãs, cujas condições são determinadas pela dinâmica de poder que obtém entre alinhamentos específicos de partes interessadas (FULLER, 2018, p.59).

\footnotetext{
${ }^{5}$ Segundo o dicionário Michaelis, tropos, para a filosofia, são argumentos com que os céticos gregos pretendiam mostrar ser possível provar a impossibilidade de se chegar à verdade (TREVISAN; WEISZFLOG, 2012).
} 
Levando os quatro pontos levantados acima em consideração, Fuller (2016b) conecta os pontos de seu argumento central afirmando que foi a partir da universalização do princípio da simetria, que estende o tratamento de todos os fatores humanos, independentemente de nossos julgamentos sobre seu mérito de verdade ou falsidade, também aos fatores não humanos, que tornou essas asserções compartilhadas por outros grupos para além dos STS. A conexão causal entre tal princípio e a emergência de uma era da pós-verdade é dada pelo autor a partir da ideia de que esses outros grupos, composto por, mas não necessariamente apenas por não-experts, tais como criacionistas, negacionistas climáticos, entre outros candidatos “a uma 'cesta de deploráveis' epistêmica” (FULLER, 2016b, p.03), passaram a aplicar o princípio da simetria por e para si mesmos. Assim, esse processo trouxe efeitos inesperados, uma vez que

ao transformar a simetria em vantagens para eles mesmos, os deploráveis obtiveram resultados, pelo menos na medida em que o equilíbrio de poder gradualmente se inclinou mais a seu favor - novamente, para melhor ou para pior (Idem).

Essa dinâmica, entretanto, vai além da perda de respeito ou de confiança na expertise científica, recaindo no que Fuller (2018), de modo negativo, interpreta como uma maior democracia epistêmica. Dito de outro modo, seu argumento é de que uma vez que os instrumentos para a produção de conhecimento são disponibilizados de forma generalizada, removendo o ar esotérico e hierárquico com que o conhecimento científico tem sido produzido, poderão ser utilizados por qualquer um com acesso a eles.

O que significa, entretanto, "aplicar o princípio da simetria para si próprios"? Quais suas consequências? Qual papel teria o princípio da simetria na conformação de uma era da pós-verdade em que qualquer um poderia, em tese, produzir conhecimento? Ou seja, uma era em que a noção de verdade perde sua legitimidade em detrimento de "notícias falsas, má ciência, e outras instâncias de 'baboseira sistemática”, conforme contra-argumenta Lynch (2017, p.598)?

\section{O princípio da simetria e sua generalização}


Para discutirmos o papel que o suspeito princípio da simetria tem na eventualidade de uma nova era marcada pelo apelo às emoções e às crenças pessoais, é de suma importância qualificarmos do que se trata, de fato, este princípio. As raízes do princípio da simetria podem ser traçadas no pioneiro artigo de David Bloor (1973), Wittgenstein and Mannheim on the sociology of knowledge, em que o autor discute um problema central na recém-criada área, deixada sem resposta por seu idealizador, Karl Mannheim: o status da lógica, da matemática, e das ciências naturais, no geral, na noção de que o conhecimento é socialmente situado. Procurando mostrar que a sociologia poderia (e deveria) penetrar na discussão eminentemente epistemológica, e considerando que o objetivo de uma sociologia do conhecimento é "explicar como as crenças das pessoas são provocadas pelas influências que atuam sobre elas”, Bloor (1973, p.173) recorre a alguns requisitos basilares ${ }^{6}$. Entre eles está a ideia de que as explicações sobre as crenças devem ser imparciais no que diz respeito à verdade e à falsidade, e ligado a essa ideia, está uma segunda: não só as crenças verdadeiras ou falsas devem ser explicadas, mas os mesmos tipos de causas devem explicar ambos os tipos de crenças.

O que Bloor (1973) propõe, e que depois foi sedimentado enquanto uma orientação metodológica no estudo sociológico empírico do conhecimento científico, no bojo de um Programa Forte de pesquisa, é, em poucas palavras, a análise simétrica daquilo que é cientificamente verdadeiro e falso (BLOOR, 2009)7 . A ideia central é que "não há nada tão especial na ciência que faça com que ela seja imune à análise sociológica [...]. O que conta como descoberta na ciência é influenciado pelo ambiente social e esta influência pode ser pesquisada" (COLLINS, 2015, p.16). Isso porque até a década de 1970,

\footnotetext{
${ }^{6}$ Bloor (2009) define conhecimento como crenças endossadas coletivamente, assumidas como certas e institucionalizadas, ou seja, distinto das crenças idiossincráticas e individuais.

7 Os quatro princípios de uma sociologia do conhecimento forte, elencados na obra Conhecimento $e$ imaginário social (2009, p.21), em sua íntegra, são os seguintes: 1) Ela deverá ser causal, ou seja, interessada nas condições que ocasionam as crenças ou os estados de conhecimento. Naturalmente, haverá outros tipos de causas além das sociais que contribuirão na produção da crença. 2) Ela deverá ser imparcial com respeito à verdade e à falsidade, racionalidade e irracionalidade, sucesso ou fracasso. Ambos os lados dessas dicotomias irão requerer explicação. 3) Ela deverá ser simétrica em seu estilo de explicação. Os mesmos tipos de causas deverão explicar, digamos, crenças verdadeiras e falsas. 4) Ela deverá ser reflexiva. Seus padrões de explicação terão que ser aplicáveis, a princípio, à própria sociologia. Assim, como a condição de simetria, essa é uma resposta à necessidade da busca por explicações gerais. É uma óbvia condição de princípio, pois, de outro modo, a Sociologia teria uma constante refutação de suas próprias teorias.
} 
a sociologia era relegada à compreensão apenas dos processos sociais exteriores à produção do conhecimento científico, que deturpavam a boa condução da ciência, ou seja, que levavam ao erro no caminho da verdade (NEVES; PINTO, 2013).

Uma das consequências epistemológicas do tratamento simétrico de crenças verdadeiras ou falsas, e da relação existente entre conhecimento científico e ordem social, é a dessacralização da imagem da ciência enquanto empreendimento autônomo em relação à sociedade (MATTEDI, 2004), ou ainda, descolado da prática humana. Como nota Neves e Pinto (2013, p.347), para que o conhecimento científico possua autonomia, é preciso separar o que é certo e errado (natureza-sociedade), o que significaria que o "conhecimento verdadeiro é obtido por meio da racionalidade e da lógica, sem interferência de outros componentes psicológicos ou sociais”, ignorando que "os conceitos de verdadeiro e falso, racional e irracional, dependem, antes de tudo, do contexto social" (Idem) em que adquirem sentido. Dessa forma, o Programa Forte inova ao propor que a prática científica se relaciona a processos sociais, tais como a formação e a dinâmica dos interesses e da negociação.

Não tardou para que Bloor fosse acusado de ser assimétrico em sua própria definição de simetria, por ser realista para a sociedade e construtivista para a natureza (LATOUR; WOOLGAR, 1997; LATOUR, 2004), debate que gerou as réplicas e tréplicas citadas na introdução deste trabalho. A crítica latouriana vai no sentido de que

\footnotetext{
a noção de simetria implica, para nós, algo mais do que para Bloor: cumpre não somente tratar nos mesmos termos os vencedores e vencidos da história das ciências, mas também tratar igualmente e nos mesmos termos a natureza e a sociedade. Não podemos achar que a primeira é dura como ferro, de modo a explicar a segunda; não podemos acreditar bravamente nas classes sociais para melhor duvidar da física (LATOUR; WOOLGAR, 1997, p.24).
}

Isso significa, em outras palavras, que esta abordagem pretende generalizar o tratamento simétrico do verdadeiro e do falso também para a natureza e a sociedade. Dessa forma, as análises tecidas por Bruno Latour, Michel Callon, entre outros colaboradores da TAR, baseiam-se na equivalência e simetria analítica entre humanos e não humanos nos processos sociotécnicos (PREMEBIDA et al, 2011). O agenciamento recíproco entre coisas e humanos indica que os não humanos expressam, se não volitivamente, ao menos na prática, as suas ações, em simetria com os humanos (MAIA, 
2015). Essa equivalência se apoia em três pontos: a) na relação de igualdade entre humanos, organismos biológicos e objetos materiais; b) na relação de implicação recíproca no agenciamento de humanos e não humanos; c) e na complementariedade entre ciência e técnica e a constante tecnificação do cotidiano das sociedades e interações humanas (PREMEBIDA et al, 2011, p.28).

Assim, na TAR, o conhecimento é visto como um produto ou efeito de uma rede de materiais heterogêneos, em que máquinas, reagentes, substâncias, artigos, organizações, cientistas e instituições sociais se ordenam e reordenam provisoriamente, sempre assumindo formas materiais, como

\footnotetext{
"um processo de "engenharia heterogênea" no qual elementos do social, do técnico, do conceitual, e do textual são justapostos e então convertidos (ou "traduzidos") para um conjunto de produtos científicos, igualmente heterogêneos. Isto é o que podemos dizer sobre a ciência. Mas eu já sugeri que a ciência não é muito especial. Assim o que é verdadeiro para a ciência é também verdadeiro para outras instituições. A família, as organizações, sistemas de computador, a economia, tecnologias - toda a vida social - podem ser similarmente descritas" (LAW, 1992, p.381).
}

Dessa forma, a generalização proposta por essa vertente de STS conserva a tentativa do Programa Forte de superar uma descrição da ciência enquanto atividade autônoma das demais práticas humanas. Acrescenta, entretanto, que a estabilização (e não mais construção) dos enunciados científicos só faz sentido dentro de seu contexto de produção, considerado a partir das "práticas, dos comportamentos e ações concretas dos cientistas em cada situação, em cada laboratório, em cada instrumento, abandonando completamente a distinção entre contexto e conteúdo" (MATTEDI, 2004, p.63). Ao equivaler diferentes atores e entidades heterogêneas inseridas na atividade científica, a vertente da TAR procura, então, analisar a estabilização do conhecimento científico através das redes de relações em que esses atores e entidades estão em movimento, levando em consideração as condições que devem ser reunidas antes mesmo que a investigação científica ocorra (Idem).

\section{A universalização da simetria, a democratização epistêmica e sua relação com a pós-verdade}


Tendo ponderado sobre a conceptualização do princípio da simetria no Programa Forte e sua subsequente generalização pela TAR, estamos aptos a prosseguir em nossa análise acerca da suposta ligação entre este princípio e o assentamento de uma era da pós-verdade. De acordo com Fuller (2016b), a era da pós-verdade seria o inevitável resultado do alargamento daqueles que podem ser considerados sujeitos epistêmicos legítimos, ou nas palavras do autor, numa maior democracia epistêmica. Essa seria a universalização do princípio da simetria a que o autor se refere, a politização promovida pelos STS deste postulado e a dissolução do privilégio epistêmico da ciência (LYNCH, 2017). De acordo com Fuller (2016a; 2016b; 2018), contrários à concepção assimétrica da atividade científica e da verdade enquanto fato objetivo, os STS, e em particular os seguidores da TAR, põem em dúvida a validade dos enunciados científicos exatamente por demonstrar, ainda na esteira de Kuhn, que a estabilização dos fatos científicos e dos paradigmas em voga perpassam valores e acordos sociais quando do surgimento de anomalias nos paradigmas já assentados. Tal politização teria chegado ao ponto de as expertises científicas serem consideradas enquanto "repositórios de julgamentos corruptos projetados para suprimir alternativas promissoras a posições já falidas" (FULLER, 2016a, s/p). Argumentamos, entretanto, na esteira de Lynch (2017), que é questionável o salto causal que Fuller empreende entre o princípio da simetria enquanto uma orientação analítica e metodológica para uma polêmica ferramenta dedicada à democratização das ciências, no sentido utilizado pelo autor, uma vez que

\footnotetext{
a simetria de Bloor estabelece estudos de controvérsias históricas, mas não resolve (e nem tenta resolver) as questões sobre verdade e falsidade que são levantadas, resolvidas ou não resolvidas pelos agentes históricos envolvidos. É um equívoco supor que os estudos em STS encorajam uma 'sociologia do erro' invertida que rebaixa a verdade, racionalidade ou sucesso da ciência estabelecida enquanto eleva o status epistêmico de uma ou outra 'alternativa promissora (LYNCH, 2017, p.597).
}

Conquanto seja discutível a tentativa ou não de avaliar e resolver as questões sobre verdade e falsidade das asserções científicas em trabalhos posteriores ao Programa Forte (BARNES; BLOOR, 1982; HADDOCK, 2004), entendemos que seria uma postura igualmente assimétrica, em termos metodológicos, dotar qualquer outra "alternativa 
promissora" como eminentemente verdadeira, sem uma análise sociológica apropriada acerca dos processos que intervém na construção e manutenção do conhecimento, sua organização e transmissão (BLOOR, 2009). Ainda, é importante ressaltar que a abordagem do Programa Forte tem um caráter vigorosamente naturalista, já que o "sociólogo está interessado pelo conhecimento, inclusive pelo conhecimento científico, puramente como um fenômeno natural", buscando "teorias que expliquem as crenças que são de fato encontradas" (BLOOR, 2009, p.17).

Apesar disso, Fuller (2016a) continua a construção de seu argumento afirmando que o pensamento simétrico, em sua universalização, tem seu tendão de Aquiles:

\footnotetext{
se o campo da ciência estiver aberto a todos, então o jogo em si pode se tornar irreconhecível. Poucos cientistas hoje em dia negam a atratividade de se estender o senso do público de uma 'cidadania científica', mas igualmente poucos o teriam transformado em uma "ciência proletária", segundo a qual a agenda de pesquisa é ditada pelo povo (FULLER, 2016a, s/p, grifos da autora).
}

A dita abertura da ciência a "todos" e a atratividade de se estender o privilégio epistêmico ao público, no geral, não passou despercebida a uma gama de trabalhos nos próprios STS. Esse campo mostra que, geralmente, o estabelecimento do que é "verdade", em detrimento de outras asserções, requer muito trabalho. Requer, mais especificamente, como apontam Collins et al (2017), um trabalho político, uma vez que a resolução de controvérsias científicas não recai apenas nos ombros do trabalho científico autônomo, socialmente esterilizado, como mostrou o Programa Forte a partir dos anos de 1970. Dessa forma, dificilmente a construção de conhecimento válido "poderia ter sido de outra forma”, uma vez que tal construção conta com estruturas bem assentadas de consenso, envolvendo uma série de esforços articulados no sentido de estabilizar os fatos científicos, aliados, laboratórios, inscrições e outros agentes heterogêneos, que por sua vez confere autoridade ao conhecimento científico (LATOUR e WOOLGAR, 1997; LATOUR, 2011). Sismondo (2017a) afirma, nesse sentido, que esse processo não se parece em nada com "pós-verdade".

Não é por acaso que trabalhos relacionados ao entendimento público de ciência e tecnologia (EPCT) mostram as dificuldades, barreiras e oposições à participação da opinião pública, ou daqueles considerados "não experts" na governança de novas 
tecnologias, controvérsias científicas e riscos associados a empreendimentos tecnocientíficos, cujos impactos negativos são incertos (JASANOFF, 2005; IRWIN, 1995; WYNNE, 1992). Epstein (1995), por exemplo, analisando a construção da expertise leiga no caso dos testes de medicamentos para portadores do vírus HIV, considera que os ativistas e movimentos sociais se utilizaram de estratégias direcionadas no sentido de negociar sua credibilidade enquanto agentes que podem contribuir ativamente na pesquisa da biomedicina. Para tanto, esse público leigo teve de aprender a "falar na linguagem da ciência”, adentrar a autoridade do conhecimento científico para serem levados em conta, e não o contrário, a fabricação de "fatos alternativos". De modo semelhante, tratando da deliberação tecnopolítica acerca da biotecnologia agrícola no Brasil no seio da Comissão Técnica Nacional de Biossegurança (CTNBio), particularmente relacionados à regulação dos Organismos Geneticamente Modificados (OGM), Fonseca (2017, p.03) argumenta que apesar de a legislação brasileira reconhecer formalmente a "necessidade de se considerar aspectos sociais e econômicos no processo de avaliação de novas biotecnologias", estes têm sido, na prática, sistematicamente invisibilizados e desconsiderados nas decisões políticas. Isto porque

\footnotetext{
"a legitimidade de decisões regulatórias de natureza sociotécnica, dentro da construção típica que tem conformado a legislação brasileira, provém de instituições que cujo mandato é isolar o conhecimento técnico e objetivo, supostamente neutro e representativo da realidade "como ela é", dos processos políticos e sociais em que ela está inserida, sujeitos a interesses e pressões particulares. Se por um lado esta fundamentação sobre os critérios de análise de biossegurança se mostra desvinculada da realidade dos processos de avaliação de risco, por outro ela revela como este dispositivo de deliberação tecnopolítica é, ele mesmo, um risco para a democracia brasileira" (FONSECA, 2017, p.16).
}

Em outras palavras, o desafio à autoridade epistêmica dos cientistas, autoridade esta que mobilizou um corpo considerável de pesquisadores em STS em busca de explicações sobre a formação, distribuição e reprodução do privilégio epistêmico da ciência e consequente democratização da ciência, não significa, dessa forma, um barateamento a grosso modo do conhecimento tecnocientífico nesse processo (SISMONDO, 2017a). Tampouco significa a abertura sistemática e plenamente democrática do privilégio epistêmico do empreendimento científico, particularmente 
em países do Sul Global, como o Brasil, como apontado por Fonseca (2017). Assim, o uso do termo pós-verdade, no contexto contemporâneo que o termo assume na política, não tem relação direta com a forma com que os STS tendem a tratar o conhecimento científico, e, porque não, o conhecimento leigo ( $\mathrm{LYNCH}, 2017)$.

Nesse ponto, é pertinente relembrar o sexto tema associado à ideia de pósverdade que Sismondo (2017b) elenca, e que dispomos no primeiro tópico deste trabalho: a perda de respeito ou de confiança na expertise científica. Os STS têm sido acusados de contribuir no declínio dessa confiança na verdade e na ciência, por "pintar uma imagem na qual todos os fatos se tornam reinvindicações e todas reivindicação são vistas como meramente políticas" (JASANOFF; SIMMET, 2017, p.752). Entretanto, além dos pontos apresentados acima, os STS reconhecem que os debates sobre fatos públicos, ou seja, aqueles fatos que projetados para persuadir os públicos, são coproduzidos em conjunto com as formas de política que as pessoas, Estados e nações desejam e praticam (JASANOFF, 2004). Ou seja, sempre foram debates sobre significados sociais, enraizados em realidades que são subjetivamente e contingencialmente experimentadas. Exemplo disso é a convergência entre conservadores da ordem econômica e política industrial, tal como o presidente Jair Bolsonaro, que desafiam não a verdade em si, mas verdades que particularmente se chocam com seus interesses, e fatos alternativos que negam consensos científicos, como as mudanças climáticas.

Assim, Jasanoff e Simmet (2017) entendem que os fatos públicos se interligam a valores políticos em pelo menos quatro maneiras: 1) A escolha de quais realidades se toma como consequência do comportamento político, assim, os fatos que consideramos importantes ou controladores são normativos; 2) As maneiras pelas quais os fatos são produzidos para servir aos interesses do governo incorporam juízos de valor anteriores sobre as formas corretas de implantar a expertise na sociedade. Isso fica claro quando se olha através de grupos sociais, nações, ou períodos históricos e se percebe que os aparelhos para fazer e contestar a verdade variam, de acordo com as histórias e promessas emancipatórias que estão associadas a afirmações específicas da verdade, a exemplo do projeto eugenista do norte-americano Charles nos anos de 1910; 3) As reivindicações de verdade na esfera pública são normativas porque reduzem o espaço para o engajamento democrático, apelando para padrões exógenos de correção, mesmo 
que estes provem, ao serem examinados, estarem profundamente carregados de valores. Este movimento trata a verdade de forma assimétrica, como se estivesse fora da dinâmica confusa da sociedade, enquanto localizando apenas desafios à verdade no mundo social; 4) Por último, "sugerindo que havia um passado preliminar no qual a verdade legitimamente precedia e guiava a política, o termo pós-verdade nega as conexões historicamente íntimas entre a construção de fatos e a ascensão da democracia moderna" (JASANOFF; SIMMET, 2017, p.752-753, grifos da autora),

Democracia essa, que, segundo Hoffman (2018), tem tudo a ver com o advento da pós-verdade num momento de enérgica "demagogia”. A "bagunça” atual aliada às notícias falsas, aos fatos alternativos e à dedicação da opinião pública em se distanciar de fatos objetivos em suas crenças e ações é a "culminação de mais de trinta décadas de uma campanha conservadora longa, muito bem financiada e altamente organizada”, cujo objetivo é "promover um universo de fatos alternativos construídos por gabinetes estratégicos conservadores, lobistas, mídia e profissionais da ciência céticos, cujo objetivo tem sido o de criar desconfiança generalizada nas principais instituições" (HOFFMAN, 2018, p.448). Concorda, assim, com os argumentos de Jasanoff e Simmet (2017), cuja crítica à ideia de pós-verdade pressupõe que a palavra "pós" indica um passado no qual as coisas foram radicalmente diferentes, e cuja perda deveria ser mundialmente lamentada, uma inocuidade a-histórica que ignora a coprodução entre conhecimento e normas em contextos políticos e científicos. A era da pós-verdade, se é que estamos nela, não é uma ruptura radical com um passado em que a política era governada pela "verdade pura”, pois como vimos, a prática política democrática sempre conectou fatos públicos com valores públicos. Dessa forma,

\footnotetext{
"As verdades públicas não podem ser ditadas - nem pela autoridade de uma ciência que sabe tudo e suas suposições de progresso social intermináveis, nem unilateralmente do trono do poder e sua vontade de dobrar a verdade aos seus propósitos. A ciência e a democracia, no seu melhor, são empresas modestas porque ambas são continuamente desconfiadas de sua própria autoridade e preferem manter suas reivindicações abertas à transparência e à crítica. Isso não significa que a busca por estabilidade na ciência ou na política deve ser descartada como quixotesca ou puramente um produto de chance cega" (JASANOFF; SIMMET (2017, p.764).
} 
O termo pós-verdade construiria, então, um falso olhar acerca da opinião pública sobre a ciência e a tecnologia, historicamente e contextualmente situada, posicionamento ao qual nos alinhamos. Dessa forma, no que diz respeito ao recente embate travado entre expoentes pesquisadores e pensadores do campo dos STS, entendemos que a discussão das consequências epistemológicas, ontológicas e políticas de seus princípios básicos são de suma importância para o desenvolvimento teórico e empírico dos próprios STS. No entanto, tais discussões seriam mais proveitosas se também tratadas enquanto exercícios intelectuais que não compusessem uma nova "guerra das ciências". Assim, evitariam que, de um lado ilações inacuradas sobre importantes discussões movidas pelos STS (a desmistificação do empreendimento científico enquanto autônomo das atividades humana, relegando aos demais grupos sociais o "erro"; a necessidade de estudos empíricos sobre a ciência, a tecnologia e suas relações com a política e com a produção de fatos, valores e fatos alternativos; e a coprodução entre democracias e a ciência e a tecnologia) os responsabilizassem pela emergência de uma nova era, e de outro lado, que as ciências sociais voltem ao estudo somente de fatores externos à prática científica.

\section{Considerações finais}

Este trabalho procurou examinar o mais recente debate promovido no campo dos STS, iniciado pelas considerações de Steve Fuller quanto à responsabilidade que o referido campo teria na conformação de uma era da pós-verdade. Esta era se caracterizaria pela influência que emoções e crenças particulares teriam na formação da opinião pública, em detrimento de dados ditos objetivos.

Procuramos, inicialmente, conceitualizar o princípio da simetria proposto por David Bloor e colaboradores no bojo de um Programa Forte em sociologia do conhecimento científico, que tinha como ponto central a desestabilização deste tipo de conhecimento enquanto o portador de um privilégio epistêmico na explicação dos fenômenos naturais. Para esta abordagem, era um pressuposto metodológico que as teorias científicas fossem analisadas de forma equivalente entre crenças verdadeiras ou falsas. Abordamos, então, a generalização deste princípio por parte dos pesquisadores 
da Teoria Ator-Rede, que, por sua vez, entendem que a análise deveria estender-se também aos elementos não humanos. Fuller argumentou, na esteira dos trabalhos da Teoria Ator-Rede, que esse princípio teria sido universalizado: agora, qualquer pessoa interessada poderia aplicar, por si mesmo, o princípio da simetria, uma vez que destituído o privilégio epistêmico da ciência, teria havido uma democratização daqueles que podem participar do jogo da construção do conhecimento confiável.

Argumentamos, entretanto, utilizando as próprias asserções e princípios norteadores dos STS, que não há uma ligação causal observável historicamente entre esse preceito teórico e uma era marcada pela mobilização de fatos alternativos, notícias falsas e mentiras deslavadas. Por fim, indicamos que é necessária a realização de pesquisas empíricas que procurem analisar as cadeias causais que levam das asserções dos STS para as táticas utilizadas por céticos das mudanças climáticas, terraplanagem e movimento 'antivax'. Por hora, concordamos com os dizeres de Jasanoff e Simmet (2017) quanto à debilidade do uso do prefixo "pós” para indicar uma ruptura a-histórica.

\section{Referências}

BARNES, Berry; BLOOR, David. Relativism, rationalism and the sociology of knowledge. In.: HOLLIS, Martin; LUKES, Steven. (Eds.). Rationality and relativism. Oxford: Blackwell, 1982.

BLOOR, David. Wittgenstein and Mannheim on the Sociology of Knowledge. Studies in History and Philosophy of Science, v. 4, n. 2, p. 173-191, 1973.

BLOOR, David. Anti-Latour. Studies in History and Philosophy of Science, v. 30, n. 1, p. 81-112, 1999.

BLOOR, David. Conhecimento e imaginário social. São Paulo: Ed. Unesp, 2009.

CALLON, Michel. Some elements of a sociology of translation: domestication of the scallops and the fishermen of St Brieuc Bay. The sociological review, v. 32, n. 1, p. 196233, 1984 .

COLLINS, Harry. Introdução: estudos sociais da ciência, a jornada. Em: PREMEBIDA, Adriano; NEVES, Fabrício; DUARTE, Tiago. (orgs.). Investigações contemporâneas em estudos sociais da ciência e tecnologia. Jundiaí: Paco Editorial, 2015. 
COLLINS, Harry; EVANS, Robert; WEINEL, Martin. STS as Science or politics? Social Studies of Sciences, v. 47, n. 4, p.580-586, 2017.

EPSTEIN, Steven. The construction of lay expertise: AIDS activism and the forging of credibility in the reform of clinical trials. Science, Technology, \& Human Values, v. 20, n. 4, p. 408-437, 1995.

DUARTE, T. R. A sociologia do conhecimento de E. Durkheim e do Programa Forte. In: PREMEBIDA, A.; NEVES, F. M.; DUARTE, T. R. (Ed.). Investigações contemporâneas em estudos sociais da ciência e tecnologia. Jundiaí: Paco Editorial, 2015.

FONSECA, Paulo. A deliberação tecnopolítica da CTNBio: uma avaliação de riscos para a democracia brasileira. Anais VII Esocite.br/tecsoc, n.4, GT-15, p.1-23, 2017.

FULLER, Steve. Science has always been a bit 'post-truth'. The Guardian, Londres, 15 dez. Disponível em: https://www.theguardian.com/science/politicalscience/2016/dec/15/science-has-always-been-a-bit-post-truth. Acesso em: 31 maio de 2020. 2016a.

FULLER, Steve. Embrace the inner fox: post-truth as the STS symmetry principle universalized. Social Epistemology Review and Reply Collective. Disponível em: http://wp.me/p1Bfgo-3nx. Acesso em: 31 maio de 2020. 2016b.

FULLER, Steve. Post-truth: knowledge as a power game. London and New York: Anthem Press, 2018.

HADDOCK, Adrian. Rethinking the "strong programme" in the sociology of knowledge. Studies in History and Philosophy of Science, v. 35, p. 19-40, 2004.

HOFFMAN, Steve. The responsibilities and obligations of STS in a moment of post-truth demagoguery. Engaging Science, Technology, and Society, v. 4, p.444-452, 2018.

IRWIN, Alan. Ciência cidadã: um estudo das pessoas: especialização e desenvolvimento sustentável. Lisboa: Edições Piaget, 1995.

JASANOFF, Sheila (ed.). States of Knowledge: The Co-Production of Science and Social Order. London: Routledge, 2004.

JASANOFF, Sheila. Designs on nature: Science and democracy in Europe and the United States. Princeton: Princeton University Press, 2005.

JASANOFF, Sheila; SIMMET, Hilton. No funeral bells: public reason in a 'post-truth' age. Social Studies of Science, v. 47, n. 5, p.751-770, 2017.

KUHN, Thomas. O caminho desde a estrutura. São Paulo: Ed. Unesp, 2003. 
LATOUR, Bruno; WOOLGAR, Steve. A vida de laboratório: a produção dos fatos científicos. Rio de Janeiro: Relume Dumará, 1997.

LATOUR, Bruno. For David Bloor... and Beyond: A Reply to David Bloor's' Anti-Latour'. Studies in History and Philosophy of Science, v. 30, p. 113-130, 1999.

LATOUR, Bruno. Jamais fomos modernos. São Paulo: Editora 34, 2004.

LATOUR, Bruno. Ciência em ação: como seguir cientistas e engenheiros sociedade afora. São Paulo: Ed. Unesp, 2011.

LATOUR, Bruno. Reagregando o social: uma introdução à Teoria Ator-Rede. SalvadorBauru: Edufba-Edusc, 2012.

LAW, John; HASSARD, John. (Eds.). Actor-network theory and after. Oxford: Blackwell Publishing/The Sociological Review, 1999.

LAW, John. Notes on the Theory of the Actor-Network: ordering, strategy and heterogeneity. System Practice, v. 5, n. 4, 1992.

LAW, John. After method: mess in social science research. Londres: Routledge, 2004.

LYNCH, Michael. STS, symmetry and post-truth. Social Studies of Science, v. 47, n. 4, p. 593-599, 2017.

MAIA, Carlos. Os impasses conceituais em Latour: o humano, o social e a simetria. Em: PREMEBIDA, A.; NEVES, F. M.; DUARTE, T. R. (orgs.). Investigações contemporâneas em estudos sociais da ciência e tecnologia. Jundiaí: Paco Editorial, 2015.

MATTEDI, Marco. Dilemas da simetria entre contexto social e conhecimento: a redefinição das modalidades de abordagem sociológica do problema do conhecimento.

Política \& Sociedade, n. 04, 2004.

MOL, Annemarie. The body multiple: ontology in medical practice. Durham and London: Duke University Press, 2002.

NEVES, Fabrício; PINTO, Vinícius. A carta de intenções de David Bloor. História, Ciência, Saúde-Manguinhos, v. 20, n. 1, 2013.

POST-TRUTH. Lexico, powered by Oxford Dictionaries. Disponível em: https://www.lexico.com/en/definition/post-truth. Acesso em: 31/05/2020. 2016.

PREMEBIDA, Adriano; NEVES, Fabrício; ALMEIDA, Jalcione. Estudos sociais em ciência e tecnologia e suas distintas abordagens. Sociologias, v. 13, n. 26, p. 22-42, 2011. 
SISMONDO, Sergio. Post-truth? Social Studies of Science, v. 47, n. 1, p. 3-6, 2017 a.

SISMONDO, Sergio. Casting a wider net: a reply to Collins, Evans and Weinel. Social Studies of Science, v. 47, n. 4, p. 587-592, $2017 \mathrm{~b}$.

SOKAL, Alan; BRICMONT, Jean. Imposturas intelectuais: o abuso da ciência pelos filósofos pós-modernos. Rio de Janeiro: Record, 2001.

TREVISAN, Rosana. (coord.); WEISZFLOG, Walter. (ed.). Michaelis: Moderno Dicionário da Língua Portuguesa. São Paulo: Melhoramentos, 2012

WYNNE, Bryan. Misunderstood misunderstanding: social identities and public uptake of science. Public Understanding of Science, v. 1, n. 3, p. 281-304, 1992. 